\title{
Standardisation of the electrical elicitation of the human flexor reflex
}

\author{
JESPER T $\varnothing$ RRING, EJNER PEDERSEN, A ND BENNY KLEMAR \\ From the Neurological Laboratory, Department of Neurology, Aarhus Kommunehospital, \\ Aarhus, Denmark
}

SUMMARY The threshold and latency of the human flexor reflex were recorded by different kinds of electrical stimuli in order to find the optimal stimulus, defined as the lowest amount of currency and the shortest possible duration. Stimulation was given over the posterior tibial nerve of the foot. The reflex response was recorded from the tibialis anterior muscle and the number and duration of the pulses and the inter-pulse interval were varied. A train of five square wave pulses with a duration of $0.5 \mathrm{~ms}$ separated by $1 \mathrm{~ms}$ were found most suitable in quantitative studies of the reflex. Twenty-four normal persons were investigated in this way as a basis for normal values. The day-to-day variations of the reflex were small in normal subjects.

Quantitative measurements of proprioceptive and exteroceptive reflexes are necessary in studies of spasticity and in the evaluation of antispastic treatment. To standardise such studies, a number of investigations were performed to find the most suitable stimulus for the elicitation of the flexor reflex. It is generally accepted that the flexor reflex is most easily elicited by repetitive stimuli, but previously different methods have been used to elicit the reflex ${ }^{1-6}$ and systematic studies have not been performed. The flexor reflex can be elicited by electrical stimulation of the plantar skin, or by electrical stimulation over the posterior tibial nerve behind the medial malleolus at the ankle. In our experience, in a pilot study of 10 normal subjects investigated on two consecutive days, the latter method gives most reproducible results. On the first day surface electrodes were placed behind the malleolus on one side and intradermal needle electrodes medial in the plantar skin of the other side. The next day the same reflex study was performed with the stimulation electrodes exchanged. The reflex response was recorded by surface electrodes from the tibialis anterior muscle. This muscle has been found most representative in the measurement of responses

Address for reprint requests: Dr E Pedersen, Department of Neurology, Aarhus Kommunehospital, Aarhus C, Denmark 8000

Accepted 26 August 1980 of the flexor reflex, ${ }^{235}$ and recordings from this muscle are not compromised by cross-talk from the antagonist muscles. ${ }^{2}$

\section{Material and methods}

The electrical stimuli were led to the patient from a constant current output unit and a digital programming unit of our own design, which allows an independent alteration of the number, interval and duration of the pulses. The stimuli were applied to the skin by surface electrodes placed 1 to $2 \mathrm{~cm}$ apart longitudinally over the posterior tibial nerve behind the medial malleolus. The flexor reflex was recorded from surface electrodes placed $5 \mathrm{~cm}$ apart longitudinally over the belly of the tibialis anterior muscle and a ground electrode also was placed on the leg. All surface electrodes were placed after carefully cleaning and rasping of the skin to reduce the impedance between the electrodes below $4 \mathrm{kOhm}$. The signals from the electrodes were fed through EMG amplifiers to the data recording equipment using video tape. ${ }^{7}$

The stimulation trials were separated into three parts. In each part, two of the three stimulation parameters were kept constant and the third was altered. The stimuli generally were separated by an interval of two minutes and were delivered randomly. The stimulation current was increased gradually from $1 \mathrm{~mA}$, in the beginning with intervals of $2.5 \mathrm{~mA}$ and later with 5 to $10 \mathrm{~mA}$. When a reflex response was obtained the stimulation current was gradually reduced until the reflex response again disappeared, but this reduction was carried out with smaller intervals. 
The lowest amplitude in $\mathrm{mA}$ able to evoke the reflex was defined as the threshold value.

Ten subjects without neurological signs and not receiving drugs participated in each part. The purpose of this study was to find the electrical stimulus which most easily evoked the flexor reflex. A stimulation with the lowest amount of current (coulomb) and shortest possible duration was found most appropriate, especially in studies including latency. From each part, the most suitable stimulation parameter was transferred to the next part and after the last part our standard stimulation parameter was defined. This standard stimulation was then applied to 24 normal subjects in order to find normal values of the reflex. Finally, day-to-day variations of the reflex were studied in 20 normal subjects, where two investigations were performed by two different investigators in each subject.

\section{Results}

In part one a stimulus consisting of five pulses separated by $1 \mathrm{~ms}$ was used. The duration of pulses was varied randomly from 0.05 to $2 \mathrm{~ms}$. The threshold was highest with the shortest duration of pulses (table 1), but a pulse duration longer than $0.5 \mathrm{~ms}$ did not result in a significant fall in the threshold (fig 1). From this part of the study a pulse duration of $0.5 \mathrm{~ms}$ was selected for further studies. In part two, five pulses with a duration of $0.5 \mathrm{~ms}$ was used. The separation of the pulses was varied randomly from $0.05 \mathrm{~ms}$ to $4.0 \mathrm{~ms}$ (table 2). No lowering of the threshold was found with a separation longer than $1 \mathrm{~ms}$ and a higher threshold was found with a separation shorter than $1 \mathrm{~ms}$. A separation of the pulses with $1 \mathrm{~ms}$ was chosen for further studies (fig 2). In part three, a duration of the pulses of $0.5 \mathrm{~ms}$ and a separation between the pulses of $1 \mathrm{~ms}$ was used and the number of pulses was varied randomly from 1 to 10 (table 3). No significant fall in the threshold was found with the number of pulses greater than five, whereas the amount of current

Table 1 Threshold of the flexor reflex. Stimulus consisting of five pulses separated by $1 \mathrm{~ms}$. Duration of pulses varied randomly. Ten subjects, 7 males and 3 females, aged 18 to 53 (average 31 ) years

\begin{tabular}{|c|c|c|c|c|c|}
\hline \multirow{2}{*}{$\begin{array}{l}\text { Duration of } \\
\text { pulses } \\
(\mathrm{ms})\end{array}$} & \multicolumn{4}{|c|}{ Threshold stimulation } & \multirow{2}{*}{$\begin{array}{l}\text { Number of } \\
\text { subjects } \\
(n)\end{array}$} \\
\hline & $\overline{\mathbf{x}} \boldsymbol{m} \boldsymbol{A}$ & $S D$ & $\overline{\mathbf{x}} \mu C$ & $S D$ & \\
\hline 0.05 & $26 \cdot 8$ & $14 \cdot 0$ & $6 \cdot 7$ & $3 \cdot 5$ & 7 \\
\hline $0 \cdot 1$ & $15 \cdot 3$ & $11 \cdot 6$ & $7 \cdot 6$ & $5 \cdot 8$ & 10 \\
\hline $0 \cdot 2$ & $14 \cdot 0$ & $9 \cdot 3$ & $14 \cdot 0$ & $9 \cdot 3$ & 8 \\
\hline $0 \cdot 3$ & $10 \cdot 7$ & $7 \cdot 9$ & $16 \cdot 0$ & $11 \cdot 8$ & 10 \\
\hline $0 \cdot 6$ & $8 \cdot 1$ & $5 \cdot 8$ & $24 \cdot 4$ & $17 \cdot 4$ & 10 \\
\hline $1 \cdot 0$ & $5 \cdot 4$ & $4 \cdot 2$ & $27 \cdot 1$ & $21 \cdot 0$ & 10 \\
\hline $2 \cdot 0$ & $5 \cdot 1$ & $3 \cdot 3$ & $51 \cdot 1$ & $32 \cdot 8$ & 10 \\
\hline
\end{tabular}

after this value seemed to increase proportional to the number of pulses (fig 3 ).

After these three parts of the study a train of five pulses each with a duration of $0.5 \mathrm{~ms}$ and separated by $1 \mathrm{~ms}$ was chosen as the standard stimulus.

The day-to-day variations of the reflex then were investigated in 20 subjects with this standard stimulation (table 4). Only small differences between the days were recorded, but the differences seem to be greater when the threshold stimulation was measured in voltage than in $\mathrm{mA}$. The differences between the mean values found by the

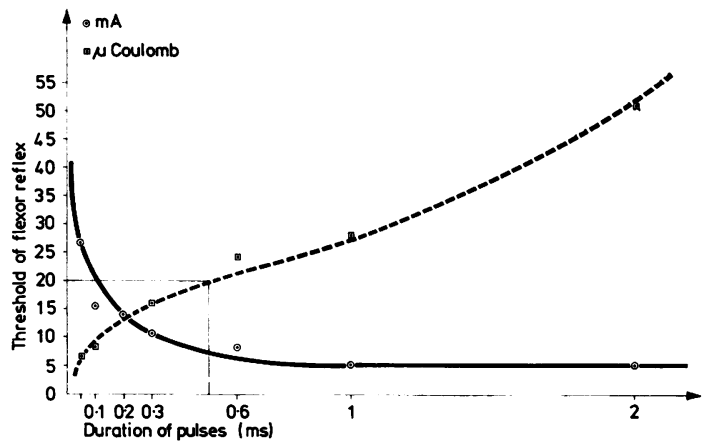

Fig 1 Threshold of the flexor reflex measured in $m A$ ( $\longrightarrow$ ) and $\mu$ coulomb (-..) as a function of the duration of pulses. Fixed stimulation parameters: five pulses separated by $1 \mathrm{~ms}$. Values represent the mean values of the 10 subjects shown in table 1.

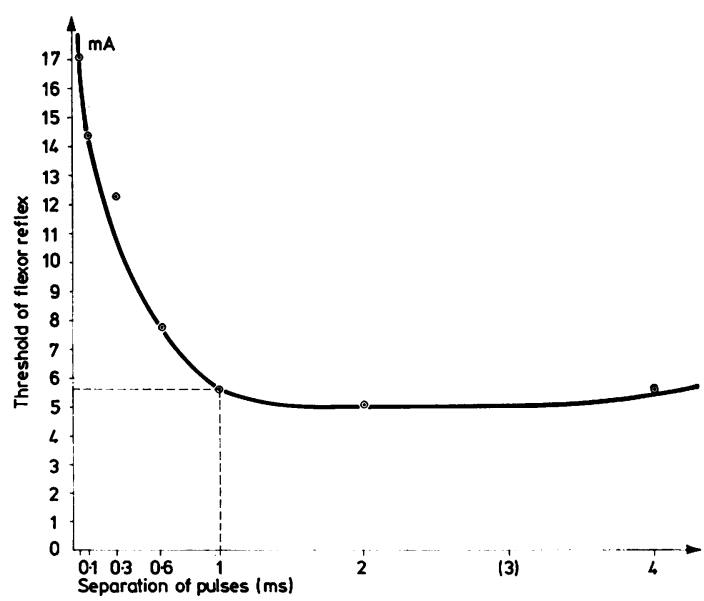

Fig 2 Threshold of the flexor reflex measured in $m A$ as a function of the separation of the pulses. Fixed stimulation parameters: five pulses with a duration of $0.5 \mathrm{~ms}$. Values represent the mean values of the nine subjects shown in table 2. 
two investigators also were small. The first investigator recorded a mean threshold stimulation of $7 \cdot 1 \mathrm{~mA}(\mathrm{SD} 4 \cdot 2)$ with a latency of $104 \mathrm{~ms}$ (SD 40) and the other investigator 6.7 $\mathrm{mA}$ (SD 3.9) and 107 ms (SD 27.8).

Measurement using the standard stimulus in 24 volunteers (all of whom had no history or signs of neurological disease and were not taking drugs) served as basis for normal values of the reflex

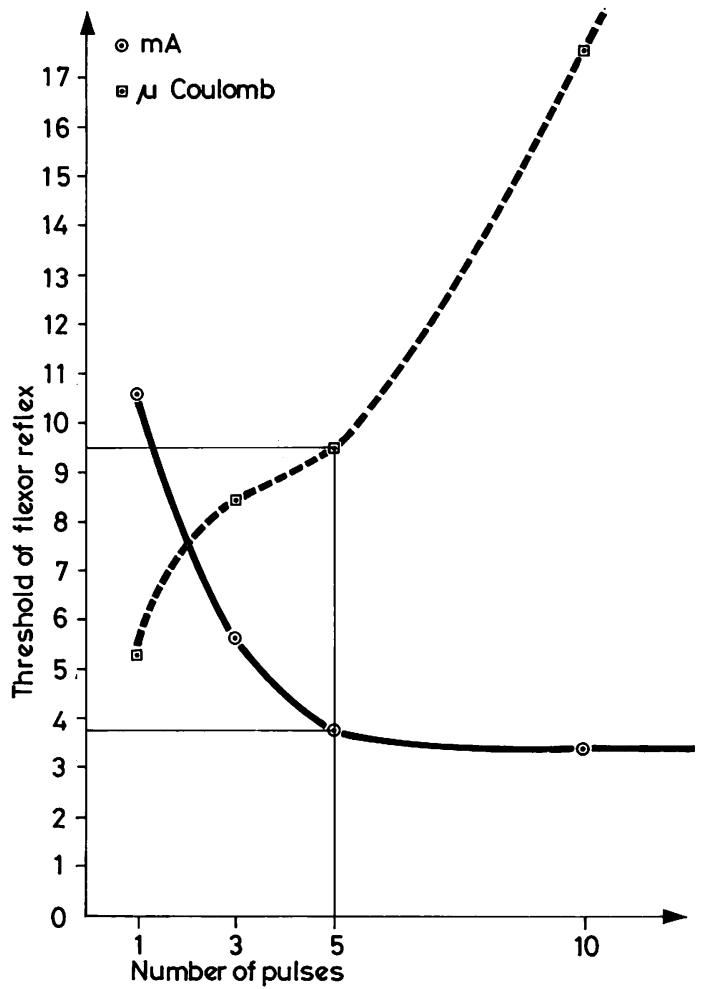

Fig 3 Threshold of the flexor reflex measured in $m A$ (-) and $\mu$ coulomb ( ...-) as a function of the number of pulses. Fixed stimulation parameters: separation of pulses $1 \mathrm{~ms}$ and the duration of pulses $0.5 \mathrm{~ms}$. Values represent the mean values of the 10 subjects shown in table 3.
Table 2 Threshold of the flexor reflex. Stimulus consisting of five pulses with a duration of $0.5 \mathrm{~ms}$. Separation of pulses varied randomly. Nine subjects, 4 males and 5 females, aged 18 to 69 (average 44) years

\begin{tabular}{llll}
\hline $\begin{array}{l}\text { Separation } \\
\text { of pulses } \\
(m s)\end{array}$ & \multicolumn{2}{l}{ Threshold stimulation } & $\begin{array}{l}\text { Number of } \\
\text { subjects } \\
(n)\end{array}$ \\
\cline { 2 - 3 } & $\bar{x} m A$ & $S D$ & 8 \\
\hline $0 \cdot 05$ & $17 \cdot 1$ & $12 \cdot 6$ & 9 \\
$0 \cdot 1$ & $14 \cdot 4$ & $9 \cdot 0$ & 8 \\
$0 \cdot 3$ & $12 \cdot 2$ & $6 \cdot 2$ & 9 \\
$0 \cdot 6$ & $7 \cdot 6$ & $4 \cdot 4$ & 9 \\
1.0 & $5 \cdot 7$ & $3 \cdot 3$ & 9 \\
$2 \cdot 0$ & $5 \cdot 2$ & $2 \cdot 7$ & 9 \\
$4 \cdot 0$ & $5 \cdot 6$ & $3 \cdot 5$ & \\
\hline
\end{tabular}

Table 3 Threshold of the flexor reflex. The number of pulses varied randomly. Separation of pulses $1 \mathrm{~ms}$. Duration of pulses $0.5 \mathrm{~ms}$. Ten subjects, 4 males and 6 females, aged 18 to 59 (average 34) years

\begin{tabular}{|c|c|c|c|c|c|}
\hline \multirow{2}{*}{$\begin{array}{l}\text { Number of } \\
\text { pulses }\end{array}$} & \multicolumn{4}{|c|}{ Threshold stimulation } & \multirow{2}{*}{$\begin{array}{l}\text { Number } \\
\text { of } \\
\text { subjects } \\
(n)\end{array}$} \\
\hline & $\bar{x} m A$ & $S D$ & $\bar{x} \mu C$ & $S D$ & \\
\hline 1 & 10.6 & $9 \cdot 3$ & $5 \cdot 3$ & $4 \cdot 6$ & 10 \\
\hline 3 & $5 \cdot 6$ & $4 \cdot 7$ & $8 \cdot 4$ & $7 \cdot 0$ & 10 \\
\hline 5 & $3 \cdot 8$ & $2 \cdot 8$ & $9 \cdot 5$ & $7 \cdot 0$ & 10 \\
\hline 10 & $3 \cdot 5$ & $2 \cdot 7$ & $17 \cdot 6$ & $13 \cdot 7$ & 10 \\
\hline
\end{tabular}

Table 5 Threshold and latency at threshold of the flexor reflex in 24 normal subjects. Stimulus consisting of five pulses with a duration of $0.5 \mathrm{~ms}$ separated by $1 \mathrm{~ms}$. Ages ranged from 14 to 69 (average 34) years. Eleven males (mean age 29 years), 13 females (mean age 38 years)

\begin{tabular}{|c|c|c|c|c|}
\hline & \multicolumn{2}{|c|}{ Threshold stimulation } & \multicolumn{2}{|c|}{ Latency at threshold } \\
\hline & $\bar{x} m A$ & $S D$ & $\bar{x} m s$ & $S D$ \\
\hline 24 normal subjects & $4 \cdot 78$ & 2.95 & $95 \cdot 0$ & 8.9 \\
\hline $\begin{array}{l}13 \text { females } \\
11 \text { males } \\
\text { Persons under } 30 \text { years } \\
(n=12, \bar{x}: 22 \text { years })\end{array}$ & $\begin{array}{l}4 \cdot 77 \\
4 \cdot 80 \\
3 \cdot 61\end{array}$ & $\begin{array}{l}2 \cdot 59 \\
3 \cdot 46 \\
2 \cdot 08\end{array}$ & $\begin{array}{l}93 \cdot 0 \\
97 \cdot 5 \\
-\end{array}$ & $\begin{array}{l}9 \cdot 0 \\
8 \cdot 5 \\
-\end{array}$ \\
\hline $\begin{array}{l}\text { Persons over } 30 \text { years } \\
(n=12, \bar{x}: 46 \text { years })\end{array}$ & 5.95 & $3 \cdot 30$ & 一 & 一 \\
\hline
\end{tabular}

Table 4 Day-to-day variations of the flexor reflex. Stimulus consisting of five pulses with a duration of $0.5 \mathrm{~ms}$, separated by $1 \mathrm{~ms}$. Twenty subjects, 11 males and 9 females, aged 14 to 65 (average 40) years

\begin{tabular}{|c|c|c|c|c|c|c|c|c|}
\hline & \multirow{2}{*}{$\begin{array}{l}\text { Number of } \\
\text { subjects } \\
(n)\end{array}$} & \multirow[t]{2}{*}{ Range } & \multicolumn{2}{|c|}{ Day one } & \multicolumn{2}{|c|}{ Day two } & \multicolumn{2}{|c|}{ Difference } \\
\hline & & & $\bar{x}$ & $S D$ & $\bar{x}$ & $S D$ & $\overline{\boldsymbol{x}}$ & $S D$ \\
\hline $\begin{array}{l}\text { Threshold stimulation, mA } \\
\text { Threshold stimulation, V } \\
\text { Latency at threshold, ms } \\
\text { Minimum latency, ms }\end{array}$ & $\begin{array}{l}19 \\
18 \\
19 \\
12\end{array}$ & $\begin{array}{l}1 \cdot 0-15 \cdot 0 \\
1 \cdot 0-38 \\
70-200 \\
50-85\end{array}$ & $\begin{array}{l}6 \cdot 88 \\
16 \cdot 2 \\
101 \\
65 \cdot 0\end{array}$ & $\begin{array}{l}3 \cdot 40 \\
12 \cdot 6 \\
23 \cdot 7 \\
8 \cdot 3\end{array}$ & $\begin{array}{c}6 \cdot 92 \\
12 \cdot 6 \\
110 \\
62 \cdot 3\end{array}$ & $\begin{array}{l}4 \cdot 58 \\
10 \cdot 2 \\
42 \cdot 8 \\
11 \cdot 0\end{array}$ & $\begin{array}{r}-0.03 \\
3 \cdot 7 \\
-8 \cdot 6 \\
2 \cdot 7\end{array}$ & $\begin{array}{l}2 \cdot 45 \\
14 \cdot 4 \\
51 \cdot 7 \\
12 \cdot 0\end{array}$ \\
\hline
\end{tabular}


(table 5). A mean threshold of $4.8 \mathrm{~mA}$ was found, equal in males and females. The younger subjects had lower threshold than elderly subjects $(p<0.025)$. The latency at threshold did not vary much in the normal subjects, and averaged about $100 \mathrm{~ms}$.

\section{Discussion}

Comparisons of studies of the flexor reflex may be difficult or impossible due to differences in the technique used, mainly that of the stimulation. This paper describes systematic studies on the electrical elicitation of the flexor reflex, which we hope will facilitate correlative studies in the future, especially as far as threshold, latency and EMG studies are concerned.

In most spastic patients the flexor reflex can be elicited by electrical stimulation of the skin anywhere in the lower limbs, but the reflex is most easily elicited by stimulation of the plantar skin. ${ }^{3}$ Electrical stimulation of the plantar skin or the afferent fibres mediating skin reception from this area therefore is most suitable to provoke the reflex. We prefer stimulation over the posterior tibial nerve, as our experience indicated better reproducibility of the reflex by this technique. This was supported by the pilot study where both types of stimulation could be compared in the same individual. The present study verified this high reproducibility obtained by electrical stimulation over the posterior tibial nerve. The day-to-day variations of the reflex were small, and we find the method described appropriate in repetitive studies, for example of the effect of drugs.

By stimulation behind the medial malleolus, not only nerve fibres but also some skin receptors will be activated. The posterior tibial nerve is a mixed nerve and both afferent and efferent fibres may be excited. By electrical stimulation of mixed nerves, Veale et $a l^{8}$ reported that pulses of a duration less than $0.2 \mathrm{~ms}$ selectively stimulate motor fibres, whereas pulses of longer duration selectively stimulate afferent fibres at threshold. The duration of pulses of $0.5 \mathrm{~ms}$ in our standard stimulus should most selectively stimulate afferent fibres. However, we of ten found small contractions of the short plantar muscles of the toes on stimulation, but no ankle movements, so it is unlikely that a stretch reflex is elicited by elongation of the tibialis anterior or the antagonist muscle to compromise the flexor response.
In the recording of the reflex response, the EMG of the anterior tibialis muscle was preferred as the most suitable representative of the reflex and it is not compromised by cross-talk from the antagonist muscles. ${ }^{2}$ Investigation of the flexor reflex is often faced with the problem that repeated provocation of the reflex leads to its reduction or disappearance. By using intervals of at least two minutes between each stimulus we met this problem inf requently.

In order to obtain reliable values of the amount of current delivered by the stimulator a reduction of the impedance of the skin below $4 \mathrm{kOhm}$ is necessary. Most stimulators have a maximum output of $200 \mathrm{~V}$ and if the impedance of the skin is for example $20 \mathrm{kOhm}$ the stimulator is only able to deliver a stimulation current of $10 \mathrm{~mA}$. This may be insufficient to elicit the reflex and is never adequate to obtain the minimal latency. Measurements of impedance are absolutely necessary in such studies.

This work was supported by a grant from the Danish League against Multiple Sclerosis.

\section{References}

1 Kugelberg E. Demonstration of $\mathrm{A}$ and $\mathrm{C}$ fibre components in the Babinski plantar response and the pathological flexion reflex. Brain 1948; 71: 304-19.

2 Pedersen E. Studies on the central pathway of the flexion reflex in man and animal. Thesis, Acta Psychiatr Neurol Scand 1954; suppl 88.

3 Dimitrijevic MR, Nathan PW. Studies of spasticity in man. 3. Analysis of reflex activity evoked by noxious cutaneous stimulation. Brain 1968; 91:349-68.

4 Dimitrijevic MR, Nathan PW. Studies of spasticity in man. 4. Changes in flexion reflex with repetitive cutaneous stimulation in spinal man. Brain 1970; 93:743-68.

5 Shahani BT, Young RR. Human flexor reflexes. J Neurol Neurosurg Psychiatry 1971; 34:616-27.

6 Horstink MWIM, Notermans SLH. Local sign in flexor reflexes. In: Persson A ed. Abstracts 6th International Congress of Electromyography. Acta Neurol Scand (suppl 73) 1979; 60:209.

7 Pedersen E, Klemar B. Recording of physiological measurements based on video technique. Scand J Rehabil Med (suppl 3) 1974; 45-50.

8 Veale JL, Mark RF, Rees S. Differential sensitivity of motor and sensory fibres in human ulnar nerve. J Neurol Neurosurg Psychiatry 1973; 36: $75-86$. 